\title{
Giuseppe MARTINICO, Lo spirito polemico del diritto europeo Studio sulle ambizioni costituzionali dell'Unione, Aracne, Roma, 2011
}

Giuseppe Martinico, joven «García Pelayo» fellow en el Centro de Estudios Políticos y Constitucionales de Madrid, ha publicado esta última obra en diciembre 2011. Se trata del resultado de años de investigación y de reflexiones presentadas en artículos precedentes y ponencias en diversas universidades europeas. Es un libro muy fluido, con un razonamiento claro, que va desde el principio hasta el final.

El objetivo principal del libro es el de reaccionar en contra de las dudas de una parte de la doctrina académica respecto a la naturaleza verdaderamente constitucional del derecho europeo (o sea, de la Unión europea). El autor destaca la importancia sistémica de los conflictos constitucionales -entre la primacía del derecho europeo y la supremacía de las constituciones nacionalespara el desarrollo de los principios constitucionales del derecho de la Unión.

En el primero de los cuatro capítulos de la obra, MARTINICO explica los conceptos esenciales que serán empleados luego: constitución europea, constitucionalismo europeo, constructivismo y evolucionismo constitucional. Además, en un análisis de los críticos de la teoría constitucional europea, se identifican unas características comunes: la referencia casi exclusiva al origen constructivista-revolucionario del constitucionalismo y la presunción de exclusividad y superioridad del constitucionalismo nacional.

En el segundo capítulo el autor trata de analizar algunas de las argumentaciones de estudiosos como Matei Avbelj, Nico Krisch y Massimo Luciani. Por un lado, MARTINICO pone de relieve la variedad de opiniones en el debate internacional. Por otro lado, el autor refuta algunos puntos fundamentales de esos enfoques, sobre todo la presunción de exclusividad del constitucionalismo nacional.

El tercer capítulo es más práctico y presenta dos ejemplos de constitucionalismo post-nacional, Canadá y Suiza. Se trata de dos ordenamientos cuya historia puede proporcionar comparaciones muy útiles para dar una luz nueva al estudio del proceso europeo, y no muy exploradas por la doctrina jurídica europeísta. MARTINICO las utiliza, de manera muy innovadora, para señalar cuales elementos frecuentemente analizados como síntomas del fracaso del constitucionalismo de la Unión Europea son, de hecho, característicos de otros contextos claramente constitucionales.

En el cuarto capítulo se examinan los conflictos. El autor aclara el horizonte teórico de sus reflexiones, empezando por Chantal Mouffe («En torno a lo político», FCE, 2007). Entonces analiza los conflictos constitucionales, especialmente aquellos juicios donde se trata de los materiales constitucionales nacionales (Mangold, Michanicki, Filipiak, Winner Wetten, Rodríguez Caballero, etc.).

MARTINICO subraya el efecto sistémico incluso de aquellos conflictos que, prima facie, parecen ser anti-sistémicos. Los conflictos tienen un papel 
esencial en la dinámica constitucional europea, porque alimentan el motor del desarrollo del sistema. El ejemplo más clásico es la jurisprudencia Solange del Tribunal constitucional federal alemán. La fuerte reacción de ese tribunal nacional ha sido el origen de una evolución sobresaliente del derecho europeo, que permitió la aceptación de principios constitucionales nacionales por la jurisdicción supranacional.

El autor intenta también encontrar otros modelos potenciales de conflictos sistémicos, por ejemplo en lo que se refiere al debate jurisprudencial sobre la autonomía del derecho procesal nacional, a partir de las Conclusiones del Abogado general Cruz Villalón en el caso Elchinov.

Tras un trabajo tan innovador, las conclusiones del autor no podían sino ser abiertas a los próximos acontecimientos del proceso constitucional europeo y al debate de los estudiosos, contrariamente a la opinión de algunos comentadores quienes lo consideran un límite. Con respecto al futuro de los conflictos constitucionales, MARTINICO considera que seguirán tomando un rol esencial en el desarrollo del derecho de la Unión. La primera razón es que los nuevos países miembros añaden heterogeneidad constitucional a la estructura del derecho europeo (lo que ha sido confirmado por ejemplo por la decisión del Tribunal constitucional checo No. Pl. US 5/12, en reacción a la sentencia del Tribunal de justicia de la Unión Landtová, C-399/09, donde los jueces checos han aplicado el control ultra vires ya profetizado por el Tribunal constitucional federal alemán en el Lissabon Urteil). En segundo lugar, el rechazo al Tratado constitucional de 2005 ha hecho explotar los conflictos latentes en el constitucionalismo europeo, entre otras razones por la terminología adoptada. Además, la adhesión de la Unión Europea al Convenio Europeo de Derechos Humanos, establecida en el Tratado de Lisboa, podría provocar una nueva "competencia interpretativa» entre los tribunales europeos, para adquirir el monopolio en el ámbito de los derechos fundamentales.

Otra causa de futuros conflictos constitucionales será sin duda la crisis financiera actual y las medidas de reacción adoptadas por la Unión y los países de la zona euro. Un ejemplo muy destacable, aunque actualmente no sea formalmente parte del derecho de la Unión, es el Tratado de Estabilidad, Coordinación y Gobernanza en la Unión Económica y Monetaria (conocido como Fiscal Compact), cuyo artículo 4.2 impone la introducción en la constitución de la regla de oro presupuestaria, lo que España hizo el 7 de septiembre de 2011.

El merito del trabajo de MARTINICO es el de presentar de manera extremadamente clara el estado actual del debate sobre el derecho constitucional europeo y, al mismo tiempo, ofrecer una perspectiva muy original. El análisis de la jurisprudencia canadiense y suiza, con un nivel elevado de pluralismo constitucional, ayuda a contrastar algunos estereotipos a menudo repetidos por una parte de la doctrina jurídica, que a veces parece exageradamente vinculada a una idea exclusivamente nacional del constitucionalismo. Las «odi- 
seas constitucionales» vividas en otros contextos demuestran que el papel de los conflictos entre actores del sistema no es un indicio de la imposibilidad de un constitucionalismo supranacional o de su fracaso, sino una manifestación de su espíritu polémico.

En otras palabras, MARTINICO nos enseña que en lugar de refutar la posibilidad de la constitucionalización de la Unión Europea, es menester analizar la manera en que este proceso se haya (aunque parcialmente) desarrollado. Y por ende, la relevancia de las reflexiones contenidas en este libro van mucho más allá del discurso exclusivamente europeo, y conciernen al mismo debate sobre los conceptos de constitución y de constitucionalismo, a veces condenados a antiguos esquemas ya no en contacto con la realidad jurídica contemporánea.

Giuseppe Bianco Ecole Normale Supérieure (Paris, France) 